\title{
Implementation of a Pilot Parent-focused Physical Activity Program with Latino Families in a Head Start Program
}

\author{
Paloma Pallante, Cristina Perales, Vanessa Rigsby, Kathleen Wilson (D), and Daniela Rubin
}

\section{California State University, Fullerton}

\begin{abstract}
Introduction and Background. Physical activity (PA), even at young age, is associated with physical and psychological health. This study determined the feasibility of implementing a parent-led PA intervention and evaluated potential outcomes. Methods. Parent-child pairs from a Head Start center were randomized into intervention $(N=20)$ and control $(N=18)$ groups. All families received a bag of play equipment. Parents completed questionnaires assessing their own and their children's PA, as well as self-efficacy, social control (SC), and social support (SS) regarding their provision of PA to their children. Parents in the intervention were trained in self-regulatory skills, facilitation of PA, and attended two playdates. Parents rated the playdates, activity sheet and equipment on a 5-point Likert scale. Results. Parents rated the playdates $(M=4.9, S D=0.3)$, the activity sheet $(M=4.7, S D=0.7)$ and the equipment bag $(M=5, \mathrm{SD}=0.0)$ highly. Child's PA, parent's moderate-to-vigorous PA, total PA, parental efficacy, SC, and SS showed no significant intervention effects. Overall, child and parent PA increased significantly over time ( $p \leq .02$ for both). Conclusions. The intervention was positively received, with $90 \%$ completion rate and high ratings of the intervention materials. Longer interventions with more contact may be needed to influence potential outcomes.

(C) 2019 and CC-BY 4.0 licensed by the authors.

Keywords: Active play, Preschool, Head Start, Families, Physical Activity, Parent's perception
\end{abstract}

\section{Introduction}

The prevalence of obesity $(13.9 \%)$ in preschool aged children (2-5 years) in the United States continues to remain considerable (Hales, Carroll, Fryar, \& Ogden, 2017). A growing imbalance among the races is present as Hispanic children have the highest prevalence of being overweight early in life (22.4\%) compared to non-Hispanic Asian children $(8.6 \%)$ and non-Hispanic white children (14.1\%) (Ogden, Carroll, Kit, \& Flegal, 2014). Some of the long-term effects of childhood obesity include physical health problems such as metabolic syndrome, type 2 diabetes, non-alcoholic fatty liver disease, obstructive sleep apnea, asthma, orthopedic complications, and cardiovascular disease (Kelsey, Zaepfel, Bjornstad, \& Nadeau, 2014; Kim, Lee, \& Lim, 2017). Additionally, shortterm effects include problems with socialization, interaction with peers, and emotional and behavioral difficulties (An, Yan, Shi, \& Yang,
2017; Griffiths et al., 2016). These problems may affect children's ability to thrive in school and need to be addressed early in life (An et al., 2017).

Child behaviors that affect weight management, such as healthy eating and physical activity (PA), are largely influenced by the monitoring, reinforcement, and modeling of their parents and/or their family environment (Webber \& Loescher, 2013). Parents who provide an environment that nurtures PA, while also engaging in and modeling PA, have a directly positive effect on their child's PA levels (Chai et al., 2019). Therefore, family-based lifestyle interventions, including dietary modifications and increased PA, are the cornerstone for weight management (Kumar \& Kelly, 2017).

Recommendations for preschool-age children indicate participation in at least 60 minutes of unstructured (free-play) and at least 60 minutes of structured (adult-led) PA each day (National 
Association of Sport and Physical Activity, 2018). However, most children ages two to five are sedentary for a large proportion (70-80\%) of their school time and achieve little time in moderate-to-vigorous PA (MVPA) (Reilly et al., 2004; Vale, Santos, Silva, Soares-Miranda, \& Mota, 2011). Contributing to the problem, parents of preschool-aged children commonly perceive that their children are participating in sufficient levels of PA (Jaballas, Clark-Ott, Clasen, Stolfi, \& Urban, 2011).

Childhood obesity has become a primary focus of Head Start programs (federally funded preschool programs for low-income families) (Early Childhood Learning and Knowledge Center, 2018). As preschool/childcare interventions can lead to increases in MVPA (Hnatiuk et al. 2019), preschools have implemented different strategies to increase PA and prevent obesity in their attendees. These strategies have included implementing PA curricula aimed at improving fundamental movement skills (Zahnd et al. 2017), engaging families by providing materials for PA and hosting family events (Davis et al., 2013), empowering parents to become involved with their children's PA (Keeney, Schneider, \& Carter, 2016), and including parents in the intervention design (Davison, Jurkowski, Li, Kranz, \& Lawson, 2013). Moreover, environmental modifications conducive to physical play or exercise or the inclusion of portable equipment have led to increased MVPA in preschoolers (Gordon, Tucker, Burke, \& Carron, 2013). Family-based interventions that promote parents as primary agents of change appear to be an effective strategy for child weight management that requires more investigation (Hammersley, Jones, \& Okely, 2016) in particular in Latino communities.

\section{The Present Study}

This study evaluated the feasibility of implementing a parent-led PA intervention through a Head Start center with Latino families. Main outcomes included child and parent PA and parental factors that potentially influence children's PA such as the use of collaborative strategies as well as social support. We hypothesized that parents in the intervention group, because of the elements provided through the intervention, would be able to provide more opportunities for PA for their child using collaborative strategies, while benefiting from the social support provided by the other families in the intervention group.

\section{Methods}

\section{Study Design}

This study was a randomized controlled pilot study. Parent and child pairs who volunteered for participation were randomly assigned to one of two groups (control or intervention).

\section{Participants}

Researchers aimed to recruit 40 from 92 potential parent-child dyads from one Head Start preschool center in Southern California. Parents were informed of the opportunity to participate in the Active Playtime study via a recruitment letter, poster boards, phone calls, and verbal and written reminders by the Head Start center staff. Thirtyeight parent-child dyads (intervention group, $\mathrm{n}=$ 20 , control group, $n=18$ ) consented to participate. All participants were Hispanic/Latino. One family dropped out in each group (intervention, $n=19$, control group, $n=17$ ). The reason for the drop out was not investigated.

\section{Head Start Center Selection}

The Head start center was chosen because it was the largest center in that particular Head Start agency allowing for the recruitment of both the control and the intervention groups from the same center. Additionally, the agency had the practice of allowing families to check out PA bags with a few elements every other week, thus eliciting a gap in the availability of PA equipment to the families. Moreover, this was the only practice in the agency to promote PA.

\section{Procedures}

Before recruitment began, this study obtained approval by the Institutional Review Board of California State University Fullerton. Parents at the Head Start agency received information about the study from agency staff. Interested parents at the Head Start center attended a meeting that described the study purpose and procedures. Afterwards, parents who enrolled in the study 
signed the informed consent form. Children of parents who provided consent provided verbal assent. The consent and assent process were completed in Spanish unless the parent requested English materials. After providing consent, all participants completed the baseline assessments (pre-visit) and were assigned to the intervention or control group using a random digit generator.

Figure. 1. Active Playtime Timeline of Study Procedures

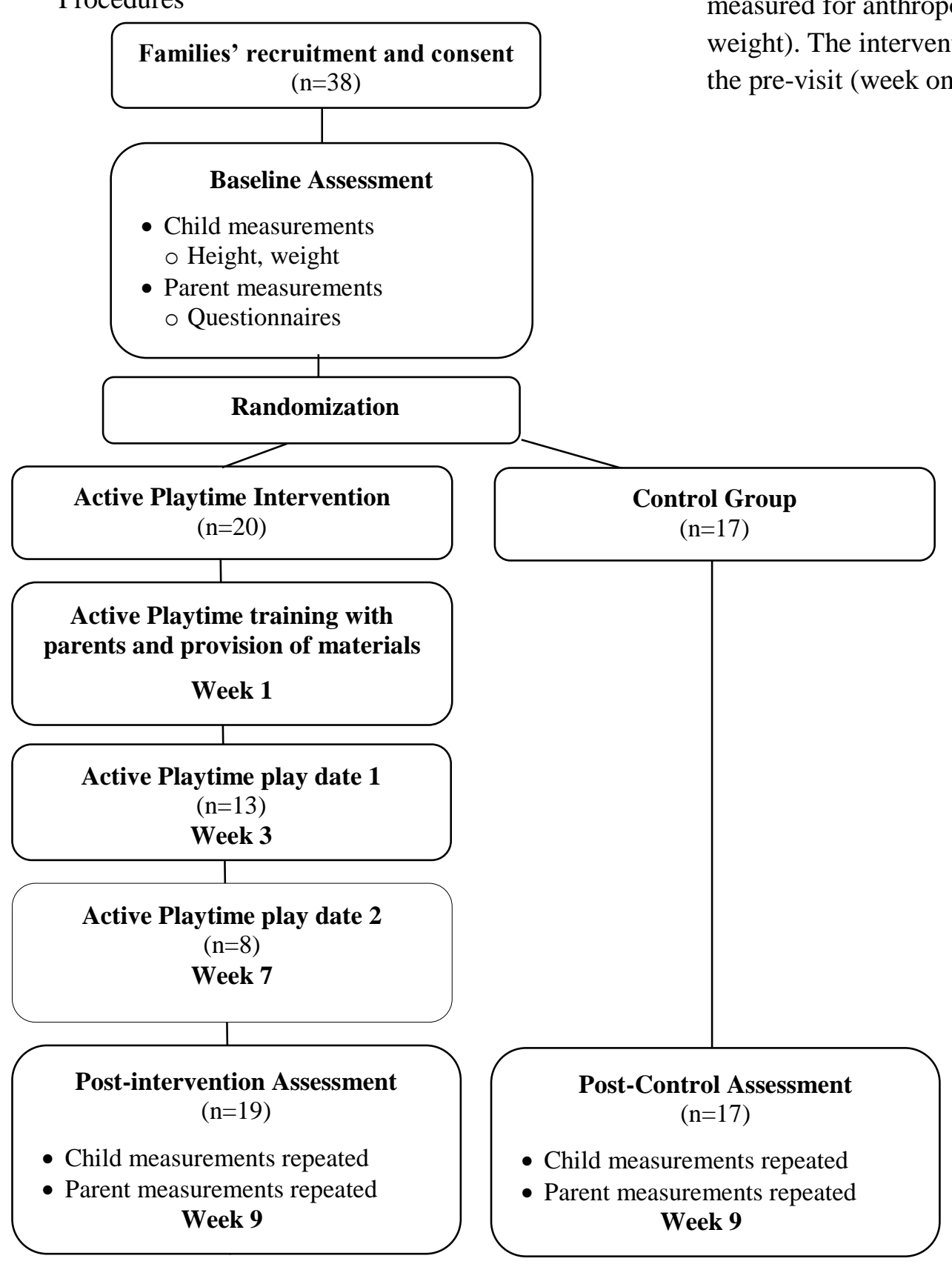

After nine weeks, families completed the postintervention visit. The visits were conducted with small groups of families based on when their child attended preschool (morning or afternoon sessions). During the pre-and postvisits, parent participants completed a questionnaire assessing social support, selfefficacy, demographics, and perceived PA of themselves and their child. Children were measured for anthropometrics (height and weight). The intervention started one week after the pre-visit (week one) (See Figure 1.). 


\section{Description of Intervention}

The Active Playtime intervention consisted of three aspects: 1) parent training to increase knowledge to provide PA for their child and parent skills (self-regulatory and leading PA); 2) provision of play and sports equipment in conjunction with an activity sheet containing examples of games and activities appropriate for children ages 3-5 years; and 3) facilitation of parent-child playdates. Parents and children met with researchers on three separate days including one training session at the beginning of the intervention (week one) and during two playdates (week three and week seven).

The parent training took place during the time children were at Head Start and involved three parts. First, the parents' received information on the benefits of having their child engage in PA, the types of activities appropriate for the age group, and how to promote and encourage PA in their children. Second, the children joined the parents and were introduced to the play equipment, the activity sheet, and participated in a practical demonstration. The equipment bag included different sized and shaped balls, a hulahoop, a frisbee disk, assorted bean bags, dome cones, a jump rope, and a scarf. Third, while the children returned to the preschool classes, the parents were introduced to regulatory skills of monitoring and coping with barriers using worksheets. The goal of the parent training included: enhancing parents' knowledge about PA, developing skills for regulating their child's PA, and building a social support network to support each other during the intervention.

During the intervention, parents were asked to engage with their child in activities using the provided play equipment. During the playdates (one to two hours long), the research team met the families at the preschool and walked with the families to a local park. The research team led new activities and games to further build the list of activities that parents could use. Parents led some activities as well. At the end of each play date, parents discussed barriers that they faced implementing PA and possible solutions. During the second playdate parents also completed a questionnaire pertaining to their experience with the activities, training, and barriers they encountered as well as general feedback. The control group did not receive the training, activity sheets, or playdates and only checked out the play equipment (i.e. rubber ball, soft ball, frisbee, and/or bean bags) every other week following standard operating procedures for this Head Start center.

\section{Measures}

Child Anthropometrics. A Seca 217 Stadiometer (Seca, Hamburg, Germany) was used to measure children's height to the nearest 0.1 centimeter and body mass was obtained using a calibrated electronic scale (ES200L, Ohaus, Pinewood, NJ) to the nearest $0.1 \mathrm{~kg}$ following the third U.S. National Health and Nutrition Examination Survey procedures from the Centers for Disease Control and Prevention (2013). Body mass index (BMI) was computed by dividing body mass $(\mathrm{kg})$ by stature $\left(\mathrm{m}^{2}\right)$ and percentiles derived from published age, sex and ethnic group specific tables published at: https://www.cdc.gov/growthcharts/percentile_da ta_files.htm.

Child's Physical Coordination. Parents completed a single item questionnaire adapted from the Amherst Health and Activity study that asked them to compare their child's motor skills to those of children of the same age and sex (Sallis, Taylor, \& Dowda, 2002). Parents responded by circling a number based on a scale of choices from one (much less) to five (much more). "Compared with other children of the same age and sex, how would you describe your child's level of physical coordination?"

Child's Physical Activity. Parents completed a single item questionnaire that asked them to compare their child's PA levels to those of children of the same age and sex. Parents responded by circling a number based on a scale of choices from one (much less) to five (much more) (Dowda, Pate, \& Sallis, 2007). "Compared with other children of the same age and sex, how much physical activity does your child do?"

Child and Parent/Guardian Demographics. Parents or guardians answered background demographic questions including their child's 
age, their sex and the sex of their child, their relationship to child, their level of education, their marital status, their ethnic background, the number of siblings at their home, the language spoken at home, and their employment status using a questionnaire.

Parent Physical Activity. The Godin Leisure Time questionnaire was used to estimate parent's total PA and MVPA levels (Godin \& Shephard, 1985). Parents reported the number of times per week they participated in leisure PA at three different levels (mild, moderate and vigorous). These frequencies were then multiplied by an arbitrary MET value to reflect the intensity of PA and then summed to compute a weekly total leisure time activity score (strenuous*9 + moderate*5 + mild*3). To obtain a score for MVPA, only the strenuous and moderate frequencies were summed.

Parental Regulatory Efficacy. Parental regulatory efficacy for managing their child's PA was measured using an adapted scale from a proxy self-efficacy questionnaire (Shields \& Brawley, 2006). This scale was originally developed for assessing perceived ability to manage one's physical activity behavior. This scale was adapted to reflect the parent's confidence to manage their child's PA. A total of nine questions were included $(\alpha=0.96)$ in which parents reported how confident they were using a rating scale ranging from $0 \%$ (not at all confident) to $100 \%$ (completely confident). The scale score was computed by averaging all nine items scores. "Over the next week, I am confident that I can help my child: 1 . Schedule physical activity sessions so that my child is active regularly."

Parental Influences. Parental influences were assessed using social control (SC) (Wilson, Spink, \& Priebe, 2010) and this reflected how parents interacted with their child. Social control was measured given the design of the intervention focused on parents taking an active role in regulating and managing their child's PA. This scale captures parent positive, collaborative and negative social influences upon the child. However, for the present study, collaborative SC scale was used as it was thought to be the most relevant type to the intervention design (e.g., playing together). This scale included three questions asking whether the parents offered to be active with their child, participated in activity so their child could see and helped their child learn skills to be active $(\alpha=0.83)$. Parents responded on a Likert scale ranging from 0 (not at all) to 7 (daily).

Social Support. Parental social support was assessed using the Social Provisions Scale (Cutrona \& Russell, 1987). This scale was used to assess the social resources that parents perceived available to them from other families within the Head Start center. The social provisions scale assesses a multidimensional model of social support by Weiss (1974). This modified scale for use in the exercise setting (Cutrona \& Russell, 1987) was further adapted to reflect the support parents received from other families in the same Head Start center. Parents were asked to rate their social support received on a scale from one (strongly disagree) to four (strongly agree). Within this current study, only the following subscales were included: social integration, reassurance of worth, reliable alliance, and guidance. Social integration assessed interactions between families and the perceived support received from other participants in the study. Reassurance of worth determined participants' abilities and whether these abilities were recognized by other participants in the study. Reliable alliance evaluated if participants could trust and/or depend on other families in the study. Guidance determined the participants' perceived support from other families regarding help or assistance with decisions. A total of twelve questions were included. The questions were divided into subscales as follow: social integration $(\alpha=0.61)$, reassurance of worth $(\alpha=0.49)$, reliable alliance $(\alpha=0.33)$, and guidance $(\alpha=0.47)$. The average score for each subscale was calculated separately. An example of a statement included, "There is no one among the "Head Start" families I can turn to for guidance about physical activity."

Assessment of the Intervention Components and Implementation. The post-assessment questionnaire included questions for parents assigned to the intervention group about overall satisfaction with the intervention and their 
favorite or least favorite parts of the intervention as well as ideas for improvements. Further, parents were asked to provide feedback on the different intervention components (parent training, equipment bag with activity sheet, and playdates) by rating the helpfulness of these elements from one (not helpful at all) to five (very helpful). During the playdates on week three and week seven, parents reported how many days in the last week they used the equipment, the activity sheet, and if they interacted with other parents from the intervention. Parents also listed the barriers that they faced and rated how limiting those barriers were on a scale from one (only slightly) to four (very limiting). This type of measure was used previously to reflect barriers to physical activity (Gyurcsik, Spink, Bray, Chad, \& Kwan, 2006).

\section{Statistical Analyses}

Descriptive statistics were computed for baseline characteristics for child and parent participants. Variables were screened for normality using standardized skewness and kurtosis scores. Parent's total PA and MVPA data were transformed using a square root transformation to obtain normal distributions. Two (group) by two (time) factorial ANOVA were used to determine PA and BMI percentile changes in children. Two (group) by two (time) factorial ANOVA were used to determine changes in parent PA, parental regulatory efficacy, social control and perceived social support. In the case of significant interactions, time or group effects, pairwise comparisons were evaluated using Tukey's posthoc tests. For all statistical comparison significance was held at $p<0.05$ and trends towards statistical significance were set at $p<0.10$. The implementation questions were evaluated using descriptive statistics. For barriers to PA and questions on intervention materials, descriptive statistics were computed including frequencies, means and standard deviations. The open-ended questions asked during the two playdates were examined to determine possible themes and/or commonalities among the participants. No a priori power calculations for effect size were conducted because this study's primary focus was determining the feasibility of implementing this PA intervention through a Head Start center.

\section{Results}

\section{Participant Characteristics}

There were no significant differences between children participants in the intervention and the control groups for baseline body mass, height, BMI, or BMI percentile at baseline $(p>0.05$ for all). Parents/guardians included 36 mothers, one father, and one grandmother. Most of the parents/guardians $(68.4 \%)$ had less than a high school degree. All participants were of Hispanic/Latino descent, and the primary language spoken at home was Spanish (See Table $1 \mathrm{a}$ and Table $1 \mathrm{~b}$.).

\section{Intervention Changes}

Child Outcomes. There were no significant group-by-time interactions or group effects for the majority of the children's outcomes $(p>0.05$ for all). There was no change in BMI percentile $(p=0.57)$ over time.

Table 1a.

Child Participant Demographics

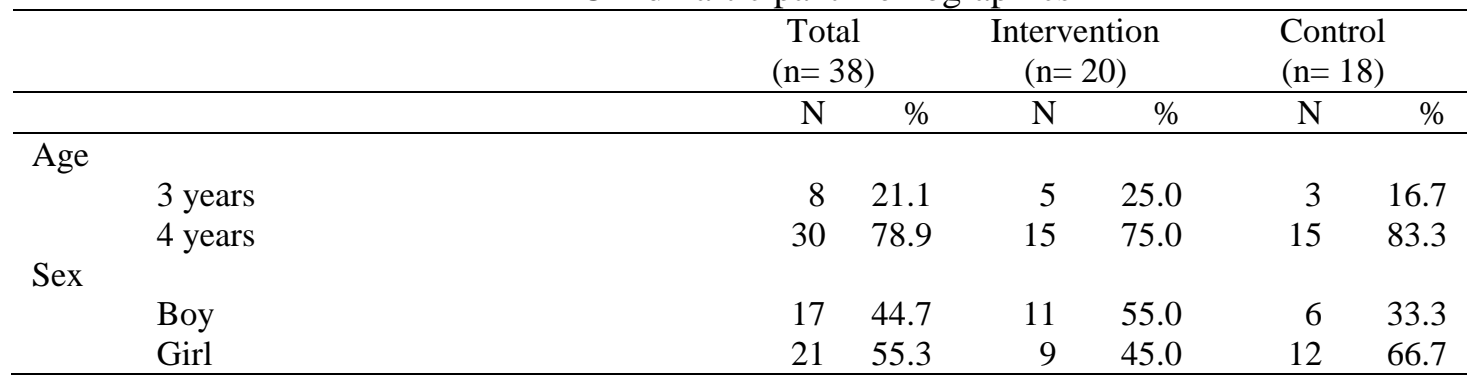


Table 1b.

Parent/Guardian Participant Characteristics

\begin{tabular}{lrrrrrr}
\hline & \multicolumn{2}{c}{$\begin{array}{c}\text { Total } \\
(\mathrm{n}=38)\end{array}$} & $\begin{array}{c}\text { Intervention } \\
(\mathrm{n}=20)\end{array}$ & \multicolumn{2}{c}{$\begin{array}{c}\text { Control } \\
(\mathrm{n}=18)\end{array}$} \\
\hline Sex & $\mathrm{N}$ & $\%$ & \multicolumn{1}{c}{$\mathrm{N}$} & $\%$ & \multicolumn{1}{c}{$\mathrm{N}$} & $\%$ \\
\hline Male & 1 & 2.6 & 1 & 5.0 & 0 & 0 \\
$\quad$ Female & 37 & 97.4 & 19 & 95.0 & 18 & 100 \\
Marital Status & & & & & & \\
$\quad$ Married & 21 & 55.3 & 11 & 55.0 & 10 & 55.6 \\
$\quad$ Single & 5 & 13.2 & 3 & 15.0 & 2 & 11.1 \\
$\quad$ Separated/Divorced & 4 & 10.5 & 3 & 15.0 & 1 & 5.6 \\
$\quad$ Other & 8 & 21.1 & 3 & 15.0 & 5 & 27.8 \\
Current occupation & & & & & & \\
$\quad$ Full-time Employment & 2 & 2.6 & 1 & 5.0 & 1 & 5.6 \\
$\quad$ Part-time Employment & 6 & 15.8 & 2 & 10.0 & 4 & 22.2 \\
$\quad$ Stay at home parent & 25 & 65.8 & 14 & 70.0 & 11 & 61.1 \\
$\quad$ Unemployed & 3 & 7.9 & 2 & 10.0 & 1 & 5.6 \\
$\quad$ Other & 2 & 5.3 & 1 & 5.0 & 1 & 5.6 \\
Highest Level of Education & & & & & & \\
$\quad$ Less than High school & 26 & 68.4 & 13 & 65.0 & 13 & 76.5 \\
$\quad$ High school Diploma/GED & 7 & 18.9 & 4 & 20.0 & 3 & 17.6 \\
Some college, College or Professional Degree & 5 & 13.2 & 3 & 15.0 & 2 & 11.1 \\
\hline
\end{tabular}

Parents reported an increase in their child's physical coordination $(3.6 \pm 0.2$ vs. $4.0 \pm 0.1$, $p=0.09)$; and levels of PA (3.5 \pm 0.2 vs. $3.9 \pm 0.1$, $p=0.02$ ) over time (See Table 2 for all values).

Parent Outcomes. There were no significant group by time interactions in parent total PA, MVPA, parental efficacy, collaborative social control, or any of the four social support components including social integration, reassurance of worth, reliable alliance, and guidance $(p \geq 0.11$ for all). There were also no group effects for any outcomes ( $p \geq 0.11$ for all). Parents total PA $(36.6 \pm 5.2$ vs. $58.3 \pm 4.9)$ and MVPA $27.0 \pm 4.1$ vs. $47.3 \pm 4.6)$ increased over time ( $p<0.01$ for both) (See Table 2 for all values).

\section{Implementation Results}

Overall Satisfaction. All parents $(n=18)$ in the intervention group rated their overall satisfaction with the program as very satisfied. Themes identified included learning new ways to promote/engage in PA (44\%), playing with other families $(22.2 \%)$ and use of equipment or activity sheet $(16.2 \%)$. For example, one participant stated that: "I learned a lot with the program for example how to create the appropriate environment to do physical activity without any importance to the weather or the location like whether it is inside or outside, I also learned different types of games (physical activities) to use with the family."

Intervention Components Ratings. Parents reported the training day to be helpful-to-very helpful answering with either a 4 or $5(M=4.8$, $S D=0.4 ; n=17)$. Thirteen families attended the first playdate and eight families attended the second playdate (6 parents completed the playdate forms at a later time). Parents rated the playdates as very helpful $(M=4.9, S D=0.3)$ and these were mentioned by nine parents $(50 \%$ of participants) as a favorite part of the program. All parents $(n=18)$ rated the equipment bag with a 5 (very helpful), and the activity sheet with $M=4.7$ $(S D=0.7)$ also as very helpful. 
Table 2.

Pre-to-post Changes for Child Characteristics and Parents' Perceptions as Providers of Physical Activity for their Children

\begin{tabular}{|c|c|c|c|c|c|c|c|c|c|}
\hline & \multicolumn{2}{|c|}{ Intervention } & \multicolumn{3}{|c|}{ Control } & \multicolumn{4}{|c|}{ ANOVA } \\
\hline & $\begin{array}{l}N=20 \\
\text { Pre }\end{array}$ & $\begin{array}{l}\mathrm{N}=19 \\
\text { Post }\end{array}$ & $\% \Delta$ & $\begin{array}{l}\mathrm{N}=18 \\
\text { Pre }\end{array}$ & $\begin{array}{l}\mathrm{N}=17 \\
\text { Post }\end{array}$ & $\% \Delta$ & $\begin{array}{l}\text { Time } \\
\mathrm{x} \\
\text { group } \\
p \\
\end{array}$ & $\begin{array}{l}\text { Group } \\
p\end{array}$ & $\begin{array}{l}\text { Time } \\
p\end{array}$ \\
\hline \multicolumn{10}{|l|}{ Children } \\
\hline Height $(\mathrm{cm})$ & $106.9 \pm 4.9$ & $108.4 \pm 4.9$ & 1.4 & $104.2 \pm 4.3$ & $105.7 \pm 4.2$ & 1.4 & 0.87 & 0.09 & $<0.01$ \\
\hline Weight $(\mathrm{kg})$ & $19.1 \pm 4.0$ & $19.6 \pm 4.1$ & 2.6 & $20.5 \pm 5.9$ & $21.3 \pm 6.2$ & 3.9 & 0.26 & 0.39 & $<0.01$ \\
\hline BMI $\left(\mathrm{kg} / \mathrm{m}^{2}\right)$ & $19.1 \pm 4.0$ & $19.6 \pm 4.1$ & 2.6 & $20.5 \pm 5.9$ & $21.3 \pm 6.2$ & 3.9 & 0.26 & 0.39 & $<0.01$ \\
\hline BMI \% tile & $73.6 \pm 30.9$ & $73.6 \pm 30.7$ & 0.0 & $71.4 \pm 28.5$ & $71.6 \pm 28.2$ & 0.2 & 0.81 & 0.64 & 0.57 \\
\hline $\begin{array}{l}\text { Physical } \\
\text { Coordination }^{\mathrm{a}}\end{array}$ & $3.8 \pm 0.8$ & $4.2 \pm 0.6$ & 10 & $3.5 \pm 1.0$ & $3.8 \pm 0.7$ & 8.5 & 0.76 & 0.07 & 0.09 \\
\hline $\mathrm{PA}^{\mathrm{a}}$ & $3.4 \pm 0.9$ & $4.0 \pm 0.7$ & 14 & $3.5 \pm 1.0$ & $3.8 \pm 0.8$ & 8.5 & 0.28 & 0.79 & 0.02 \\
\hline \multicolumn{10}{|l|}{ Parents } \\
\hline Self-Efficacyb & $86.5 \pm 16.9$ & $85.3 \pm 15.4$ & 1.3 & $81.4 \pm 20.7$ & $74.9 \pm 17.5$ & -7.9 & 0.41 & 0.13 & 0.34 \\
\hline $\begin{array}{l}\text { Social } \\
\text { Control }^{c}\end{array}$ & $4.5 \pm 1.9$ & $4.7 \pm 1.4$ & 4.4 & $4.1 \pm 1.5$ & $3.6 \pm 1.6$ & -12 & 0.26 & 0.13 & 0.55 \\
\hline $\begin{array}{l}\text { Social } \\
\text { Integration }^{\mathrm{d}}\end{array}$ & $3.1 \pm 0.5$ & $3.0 \pm 0.4$ & 3.0 & $3.2 \pm 0.4$ & $2.9 \pm 0.6$ & -9.0 & 0.34 & 0.82 & 0.39 \\
\hline $\begin{array}{l}\text { Reassurance } \\
\text { of Worth }\end{array}$ & $2.3 \pm 0.6$ & $2.4 \pm 0.4$ & 4.0 & $2.3 \pm 0.6$ & $2.4 \pm 0.4$ & 4.0 & 0.83 & 0.70 & 0.58 \\
\hline $\begin{array}{l}\text { Reliable } \\
\text { Alliance }^{\mathrm{d}}\end{array}$ & $3.0 \pm 0.5$ & $3.0 \pm 0.4$ & 0.0 & $2.7 \pm 0.8$ & $3.0 \pm 0.6$ & 11 & 0.58 & 0.83 & 0.28 \\
\hline Guidance $^{\mathrm{d}}$ & $3.0 \pm 0.4$ & $2.9 \pm 0.5$ & 3.0 & $2.8 \pm 0.5$ & $3.2 \pm 0.6$ & 14 & 0.11 & 0.11 & 0.30 \\
\hline MVPA $^{\mathrm{a}}$ & $25.6 \pm 23.2$ & $46.4 \pm 26.3$ & 81 & $28.5 \pm 25.6$ & $48.2 \pm 28.3$ & 69 & 0.73 & 0.90 & $<0.01$ \\
\hline $\mathrm{TPA}^{\mathrm{a}}$ & $35.9 \pm 27.7$ & $59.6 \pm 28.7$ & 66 & $37.3 \pm 33.1$ & $57.1 \pm 29.7$ & 53 & 0.95 & 0.74 & $<0.01$ \\
\hline
\end{tabular}

a. Scale: 1 (less) - 5 (more)

b. Scale: $0 \%$ (not at all confident) - 100\% (completely confident)

c. Scale 0 (not at all) -7 (daily)

d. Scale 1 (strongly disagree) -5 (strongly agree)

PA = Physical Activity, MVPA= Moderate-to- Vigorous Physical activity, TPA=Total Physical Activity

Parents reported using the equipment and the activity sheet an average of 3.9 days $(S D=1.1)$ and of 2.8 days $(S D=2.1)$ per week at playdate one $(N=13)$ and 3.4 days $(S D=1.7)$ and 2 days $(S D=1.7)$ per week at playdate two $(N=14)$. At both playdates (playdate 1: $n=13$; playdate 2 : $n=14$ ), participants used the ball (playdate 1 : $38.5 \%$; playdate $2: 57.1 \%$ ) and the hula hoop (playdate 1: $30.8 \%$; playdate 2: $35.7 \%$ ).

Barriers to Intervention Implementation. The most common barriers included: 1) time, 2) sickness or injury, 3) prior obligations. A few participants ( $n=2$ each playdate) reported other responses that could not be grouped with previous barriers and included weather barriers and personal issues like moving and fixing their house (See Table 3).

Improvements to the Intervention. Suggested improvements included a longer duration program as well as more activities with other families. It was suggested the intervention provided more games or sample activities and more training on their implementation. Parents also wanted to have the equipment permanently in their homes. 
Table 3.

Parent-reported Barriers/Limitations to Providing Physical Activity for their Children

\begin{tabular}{|c|c|c|c|c|}
\hline & \multicolumn{2}{|c|}{ Playdate $1(n=13)$} & \multicolumn{2}{|c|}{ Playdate $2(n=14)$} \\
\hline & $\mathrm{n}^{\mathrm{b}}(\%)$ & Range $^{c}$ & $\begin{array}{r}\mathrm{n}^{\mathrm{b}} \\
(\%)\end{array}$ & Range $^{c}$ \\
\hline Time & $\begin{array}{r}4 \\
(30.8 \%)\end{array}$ & 3 & $\begin{array}{r}5 \\
(35.7 \%)\end{array}$ & 1 \\
\hline $\begin{array}{l}\text { Being } \\
\text { sick/hurt }\end{array}$ & $\begin{array}{r}4 \\
(30.8 \%)\end{array}$ & 1.33 & $\begin{array}{r}6 \\
(42.9 \%)\end{array}$ & 3.33 \\
\hline $\begin{array}{l}\text { Prior } \\
\text { Obligations }\end{array}$ & $\begin{array}{r}4 \\
(30.8 \%)\end{array}$ & 1.25 & $\begin{array}{r}1 \\
(7.1 \%)\end{array}$ & 3 \\
\hline Other & $\begin{array}{r}2 \\
(15.4 \%) \\
\end{array}$ & 2.5 & $\begin{array}{r}2 \\
(14.3 \%) \\
\end{array}$ & 2.67 \\
\hline
\end{tabular}

Note. Only 8 families attended the playdate \#2 with 6 families completing the questionnaire at the preschool at a later time.

b. with the option to list multiple barriers, the percentages do not add up to $100 \%$.

c. Range: 1 (only slightly limiting) - 4 (very limiting).

\section{Discussion}

The aim of this study was to pilot a parentfocused home-based PA intervention implemented through a Head Start center, and to explore changes in children and parent PA, as well as in parents reported social support, social control and regulatory efficacy. The study showed no significant differences between the intervention and control groups over time. In both groups, parents reported an increase in their child's PA and their own PA over time. There were no changes in the behavioral mediators of PA in the parents (e.g., parental efficacy, parental influences and support). Parents highly rated the intervention materials and components.

\section{Parent-reported Body Coordination}

Intervention Effects. According to their parents, children improved their body coordination. This was expected due to maturational changes (Schneiberg, Sveistrup, McFadyen, McKinley, \& Levin, 2002). However, we expected to see that the intervention group demonstrated further gains than the control group. Because the majority of PA interventions that improved motor skills have been longer than eight weeks (Han, Fu, Cobley, \& Sanders, 2018; Wick et al., 2017; Zeng et al., 2017), it is possible the length of this intervention was not enough. It is also possible that the lack of group differences is related to the measurement tool used. Parents rated their child's body coordination using a one to five scale that compared their child's body coordination in relationship to other children. As participants for control and intervention groups attended the same center, contamination might have occurred.

Intervention Effects on Parent-reported PA. Children and parent participants increased PA regardless of their group. One reason for the perceived increase in PA in both groups might be that all participants received the same equipment bags. Both groups received an improved version of the equipment bags that were allowed for check out at the Head Start center before the intervention begun. However, the intervention group kept the bag during the eight weeks while the control had to return it every other week. Previously, Gubbels et al. (2011) demonstrated that outdoor PA in children was positively associated with the availability of portable jumping equipment in childcare centers. Verstraete, Cardon, De Clercq, \& De Bourdeaudhuij. (2006) showed that providing game equipment during morning recess and lunch break in elementary schools resulted in increased children's MVPA. Thus, since both groups received the equipment bags, an increase in PA could be expected. Perhaps receiving the equipment bags led to children being more active or demonstrating interest or enjoyment of PA, hence influencing parents' perceptions in both groups (Bentley et al., 2012). It is also possible that the increased awareness about PA in their child and themselves possibly led to bias in selfreport. Last, while some studies have shown increases in PA in children through different intervention strategies (Hnatiuk et al., 2019) other studies have not been successful at this goal (Adamo et al., 2017).

Intervention Effects on Parent Self-efficacy. Parents in the intervention group were introduced to the concept of self-monitoring, action plans, coping with barriers and were also provided knowledge to help them guide their child's PA. Other interventions that incorporated similar techniques have either shown improvement in the levels of self-efficacy of their adult participants (Cramp \& Brawley, 2006) or in the children's PA 
of the parent participants (Miller, Trost, \& Brown, 2002). Within Bandura's Social Cognitive Theory (1986), self- regulation becomes one of the fundamental structures of human organization, ultimately affecting a perceived self-efficacy in a PA setting. Although not statistically significant, parents' efficacy appeared to change differently between the groups as parents in the intervention showed no change and those in the control group demonstrated an $8 \%$ decrease. This difference is important because while intervention parents had to cope with new challenges, new equipment, and a new level of required time management, their perceived parental efficacy did not decrease over the eight weeks. When new exercisers begin a routine, perceived efficacy has been reported to decrease at the initial stages (DuCharme \& Brawley, 1995). It is possible that the regulatory strategies presented in the training for parents might have contributed to preventing the decrease in efficacy (Arbour-Nicitopoulos, Ginis, \& Latimer, 2009).

Intervention Effects on Parental Collaborative Social Control. In terms of how the parents interacted with their children, parents in the intervention showed a slight increase (4\%) in the use of collaborative social control, with those in the control group showing a $12 \%$ decrease in social control. Active Playtime focused on having parents promote PA in their children by being active with them and using collaborative social control. Although social control by parents targeting PA has received little attention in the literature (Cotter, 2012), collaborative social control is the type of social control that has been associated with positive PA behavior in adolescents (Wilson \& Spink 2011). The differences in percent change between the two groups may indicate a positive outcome as parents in the intervention group reported engaging more with their child to promote PA than the parents in the control group.

Intervention Effects on Parents' Perceived Social Support from Other Parents. Given the intervention included playdates for families, perceived social support was expected to increase in participants. One goal of the playdates was to increase the social interaction with other parents from the Head Start center. However, as shown in another study (Anderson, Wojcik, Winett, \& Williams, 2006), there were no changes in perceived social support. Potentially, the amount of interaction fostered through the playdates was insufficient, another avenue of interaction may be needed such as social media (DeHoff, Staten, Rodgers, \& Denne, 2016), or the playdates were simply social events. It is also possible that the instrument used to assess social support limited detecting changes. The social support questions used referred to families from the Head Start center but did not specify about families in the intervention group. Because this was a pilot study to determine the feasibility of the intervention strategy as well as evaluation of the assessment tools, allocating entire centers from the agency to either a control or intervention group to avoid contamination was neither prioritized nor possible. Thus, potentially contamination occurred. Last, the social support scales used in this study had poor-fair internal reliability or consistency within this sample, limiting the interpretation of their results.

Participant Program Satisfaction. Although there were no significant changes identified in the targeted outcomes, the intervention was well received by participants. They reported high levels of satisfaction and value for the resources provided (i.e. equipment, activity sheet and playdates), and specific elements (i.e. ball and hula hoop) based on the reported use. Participants expressed that the intervention duration was short. A longer intervention may allow changes on study outcomes to emerge that were not seen in this pilot such as body coordination (Han et al., 2018; Wick et al., 2017; Zeng et al., 2017). Challenges that parents reported were time constraint, being sick (them or their child), and prior obligations. The barriers of lack of time and weather are similar to those reported before (Lindsay, Sussner, Greaney, \& Peterson, 2009). However, parents rated time in the first playdate as a limiting factor, and on the second playdate time was rated only slightly limiting, suggesting parents learned to cope with time as a limiting factor. 


\section{Limitations}

This pilot study presented some limitations. This intervention was implemented using the structure of a Head Start center serving primarily Latino families, limiting generalization to other groups. The intervention time (eight weeks), might not have been enough to impact the mediators of change. Self-reported PA may be biased due to lack of accuracy and over-reporting (Corder, Crespo, van Sluijs, Lopez, \& Elder, 2012). Additionally, for the child, a single item measure was used that asked for a comparison of PA levels, the item did not ask for specific measurements such as time or volume of PA. This presents possible issues of accuracy. In addition, the Godin Leisure questionnaire included example activities that were not part of the Active Playtime intervention, hence, limiting the ability to detect a change in the parents' PA. We attempted to measure PA using accelerometry; however, due to technical difficulties with the setup of different accelerometer models and poor compliance with wear time, data were collected in only nine participants and not valid for interpretation. Families were encouraged to be active every day, but there was no specific suggested PA dose.

In the present study, the individual subscales of the social support questionnaire showed poor internal consistency, despite being a validated and reliable instrument in other populations (Cutrona \& Russel, 1987; Gottlieb \& Bergen, 2010). This questionnaire has been translated and validated into other languages such as French \& Portuguese (Gottlieb \& Bergen, 2010); however a Spanish translation was utilized in this study. Additionally, the intervention was designed to build social support within the participants in the intervention group, but the social support questions asked participants to think about other parents from the Head Start center not specifically parents in the intervention group. Hence, parents may have thought about all parents in the center regardless of whether they were assigned or not to the intervention group potentially contributing to some variability in the responses. As this pilot study was conducted with the goal of identifying potential measures that are appropriate to use in the future, the low internal consistency of the social support scale suggests that this instrument may not be appropriate with future interventions with a similar population or study design or may need further adaptations. Finally, there was a language barrier between participants and researchers.

\section{Conclusion}

The Active Playtime intervention did not result in any increases in levels of PA in parent or child participants or in any changes in the hypothesized mediators of change: self-efficacy, parental influences, and social support. It appears that the intervention elements (parent training materials, activity sheet, as well as the interaction opportunities with the children and other families) were well received by the families and within a preschool environment. Considering that only two families dropped out of the study, it appears that this type of intervention is feasible and could be implemented using the existing infrastructure of Head Start programs using a longer time frame and/or more in-depth engagement through playdates.

\section{References}

Adamo, K. B., Wasenius, N. S., Grattan, K. P., Harvey, A. L. J., Naylor, P. J., Barrowman, N. J., \& Goldfield, G. S. (2017). Effects of a preschool intervention on physical activity and body composition. Journal of Pediatrics, 188 (42-49), 42. doi:10.1016/j.jpeds.2017.05.082

An, R., Yan, H., Shi, X., \& Yang, Y. (2017). Childhood obesity and school absenteeism: A systematic review and meta-analysis. Obesity Reviews, 18(12), 1412-1424. doi:10.1111/obr.12599

Anderson, E. S., Wojcik, J. R., Winett, R. A., \& Williams, D. M. (2006). Social-cognitive determinants of physical activity: The influence of social support, self-efficacy, outcome expectations, and selfregulation among participants in a church-based health promotion study. Health Psychology, 25(4), 510-520. doi:10.1037/0278-6133.25.4.510 
Arbour-Nicitopoulos, K. P., Ginis, K. A., \& Latimer, A. E. (2009). Planning, leisure-time physical activity, and coping self-efficacy in persons with spinal cord injury: A randomized controlled trial. Archives of Physical Medicine Rehabilitation, 90(12), 2003-2011. doi:10.1016/j.apmr.2009.06.019

Bandura, A. (1986). Social foundations of thought and action: A social cognitive theory. Englewood Cliffs, NJ: Prentice-Hall.

Bentley, G. F., Goodred, J. K., Jago, R., Sebire, S. J., Lucas, P. J., Fox, K. R., . . Turner, K. M. (2012). Parents' views on child physical activity and their implications for physical activity parenting interventions: A qualitative study. BMC Pediatrics, 12, 180. doi:10.1186/1471-2431-12-180

Chai, L., Collins, C., May, C., Brain, K., Wong See, D., \& Burrows, T. (2019). Effectiveness of familybased weight management interventions for children with overweight and obesity: An umbrella review. JBI Database of Systematic Reviews and Implementation Reports, 17(7), 1341-1427.

Centers for Disease Control and Prevention. BMI percentiles data files. Available at:

https://www.cdc.gov/growthcharts/percentile_data_files.htm. Accessed April 1, 2014.

Corder, K., Crespo, N. C., van Sluijs, E. M. F., Lopez, N. V., \& Elder, J. P. (2012). Parent awareness of young children's physical activity. Preventive Medicine, 55(3), 201-205. doi:10.1016/j.ypmed.2012.06.021

Cotter, K. A. (2012). Health-related social control over physical activity: Interactions with age and sex. Journal of Aging Research, 2012, 321098. doi:10.1155/2012/321098

Cramp, A. G., \& Brawley, L. R. (2006). Moms in motion: A group-mediated cognitive-behavioral physical activity intervention. International Journal of Behavioral Nutrition and Physical Activity, 3, 23. doi:10.1186/1479-5868-3-23

Cutrona, C. E., \& Russell, D. W. (1987). The provisions of social relationships and adaptation to stress. Advances in Personal Relationships, 1, 37-67.

Davis, S. M., Sanders, S. G., FitzGerald, C. A., Keane, P. C., Canaca, G. F., \& Volker-Rector, R. (2013). CHILE: An evidence-based preschool intervention for obesity prevention in Head Start. Journal of School Health, 83(3), 223-229. doi:10.1111/josh.12018

Davison, K., Jurkowski, J., Li, K., Kranz, S., \& Lawson, H. (2013). A childhood obesity intervention developed by families for families: Results from a pilot study. International Journal of Behavioral Nutrition and Physical Activity, 10(1), 3. doi:10.1186/1479-5868-10-3

DeHoff, B. A., Staten, L. K., Rodgers, R. C., \& Denne, S. C. (2016). The role of online social support in supporting and educating parents of young children with special health care needs in the United States: A scoping review. Journal of Medical Internet Research, 18(12), 333. doi:10.2196/jmir.6722

Dowda, M., Pate, R.R., Sallis, J.F., Freedson, P.S., Taylor, W.C., Sirard, J.R., and Trost, S.G. (2007). Agreement between student-reported and proxy-reported physical activity questionnaires. Pediatric Exercise Science, 19, 310-318.

DuCharme, K. A., \& Brawley, L. R. (1995). Predicting the intentions and behavior of exercise initiates using two forms of self-efficacy. Jounral of Behavioral Medicine, 18(5), 479-497.

Early Childhood Learning and Knowledge Center [ECLKC], Retrieved September 2018, from https://eclkc.ohs.acf.hhs.gov/about

Godin, G., \& Shephard, R. J. (1985). A simple method to assess exercise behavior in the community. Canadian Jounral of Applied Sport Sciences, 10(3), 141-146.

Gordon, E. S., Tucker, P., Burke, S. M., \& Carron, A. V. (2013). Effectiveness of physical activity interventions for preschoolers: A meta-analysis. Research Quarterly for Exercise and Sport, 84(3), 287-294. doi:10.1080/02701367.2013.813894

Gottlieb, B., \& Bergen, A. (2010). Social support concepts and measures. Journal of Psychosomatic Research, 69(5), 511-520.

Griffiths, L. J., Sera, F., Cortina-Borja, M., Law, C., Ness, A., \& Dezateux, C. (2016). Objectively measured physical activity and sedentary time: Cross-sectional and prospective associations with 
adiposity in the Millennium Cohort Study. BMJ Open, 6(4), 010366. doi:10.1136/bmjopen-2015010366

Gubbels, J. S., Kremers, S. P., van Kann, D. H., Stafleu, A., Candel, M. J., Dagnelie, P. C., . . de Vries, N. K. (2011). Interaction between physical environment, social environment, and child characteristics in determining physical activity at child care. Health Psychology, 30(1), 84-90. doi:10.1037/a0021586

Gyurcsik, N. C., Spink, K. S., Bray, S. R., Chad, K., \& Kwan, M. (2006). An ecologically based examination of barriers to physical activity in students from grade seven through first-year university. Journal of Adolescent Health, 38(6), 704-711. doi:10.1016/j.jadohealth.2005.06.007

Hales, C., Carroll, M., Fryar, C., \& Ogden, C. (2017). Prevalence of obesity among adults and youth: United States, 2015-2016. NCHS Data Brief, (288), 1-8.

Hammersley, M. L., Jones, R. A., \& Okely, A. D. (2016). Parent-focused childhood and adolescent overweight and obesity eHealth interventions: A systematic review and meta-analysis. Journal of Medical Internet Research, 18(7), e203. doi:10.2196/jmir.5893

Han, A., Fu, A., Cobley, S., \& Sanders, R. H. (2018). Effectiveness of exercise intervention on improving fundamental movement skills and motor coordination in overweight/obese children and adolescents: A systematic review. Journal of Sports and Science Medicine, 21(1), 89-102. doi:10.1016/j.jsams.2017.07.001

Hnatiuk, J. A., Brown, H. E., Downing, K. L., Hinkley, T., Salmon, J., \& Hesketh, K. D. (2019). Interventions to increase physical activity in children $0-5$ years old: A systematic review, metaanalysis and realist synthesis. Obesity Reviews, 20(1), 75-87. doi:doi:10.1111/obr.12763

Jaballas, E., Clark-Ott, D., Clasen, C., Stolfi, A., \& Urban, M. (2011). Parents' perceptions of their children's weight, eating habits, and physical activities at home and at school. Journal of Pediatric Health Care, 25(5), 294-301. doi:10.1016/j.pedhc.2010.05.003

Keeney, J., Schneider, K. L. \& Carter, J. S. (2016). The influence of parent involvement on child physical activity. Medicine and Science in Sports and Exercise, 48(5), 700-713

Kelsey, M. M., Zaepfel, A., Bjornstad, P., \& Nadeau, K. J. (2014). Age-related consequences of childhood obesity. Gerontology, 60(3), 222-228. doi:10.1159/000356023

Kim, J., Lee, I., \& Lim, S. (2017). Overweight or obesity in children aged 0 to 6 and the risk of adult metabolic syndrome: A systematic review and meta-analysis. Journal of Clinical Nursing, 26(2324), 3869-3880. doi:10.1111/jocn.13802

Kumar, S., \& Kelly, A. S. (2017). Review of childhood obesity: from epidemiology, etiology, and comorbidities to clinical assessment and treatment. Mayo Clinic Proceedings Journal, 92(2), 251265. doi:10.1016/j.mayocp.2016.09.017

Lindsay, A. C., Sussner, K. M., Greaney, M. L., \& Peterson, K. E. (2009). Influence of social context on eating, physical activity, and sedentary behaviors of latina mothers and their preschool-age children. Health Education Behavior, 36(1), 81-96. doi:10.1177/1090198107308375

Miller, Y. D., Trost, S. G., \& Brown, W. J. (2002). Mediators of physical activity behavior change among women with young children. American Journal of Preventative Medicine, 23(2), 98-103.

National Health and Nutrition Examination Survey (2013). Centers for Disease Control and Prevention. Retrieved August 2013, from http://www.cdc.gov/nchs/nhanes.htm.

National Association Sport and Physical Education (2018). A wealth of play and playground information at your fingertips. Retrieved August 31, from https://www.pgpedia.com/n/national-associationsport-and-physical-education.

Ogden, C., Carroll, M., Kit, B., \& Flegal, K. (2014). Prevalence of childhood and adult Obesity in the United States, 2011-2012. Journal of the American Medical Association, 311(8), 806-814.

Reilly, J. J., Jackson, D. M., Montgomery, C., Kelly, L. A., Slater, C., Grant, S., \& Paton, J. Y. (2004). Total energy expenditure and physical activity in young scottish children: Mixed longitudinal study. Lancet, 363(9404), 211-212. 
Sallis, J.F., Taylor, W.C., Dowda, M., Freedson, P.S., and Pate, R.R. (2002). Correlates of vigorous physical activity for children in grades 1 through 12: Comparing parent-reported and objectively measured physical activity. Pediatric Exercise Science, 14, 30-44.

Schneiberg, S., Sveistrup, H., McFadyen, B., McKinley, P., \& Levin, M. F. (2002). The development of coordination for reach-to-grasp movements in children. Experimental Brain Research, 146(2), 142-154. doi:10.1007/s00221-002-1156-z

Shields, C. A., \& Brawley, L. R. (2006). Preferring proxy-agency: Impact on self-efficacy for exercise. Journal of Health Psychology, 11(6), 904-914. doi:10.1177/1359105306069092

Vale, S., Santos, R., Silva, P., Soares-Miranda, L., \& Mota, J. (2011). Relationship of objective measurement of physical activity during school hours and BMI in preschool children. International Journal of Pediatric Obesity, 6(2), 37-38. doi:10.3109/17477166.2011.613663

Verstraete, S. J., Cardon, G. M., De Clercq, D. L., \& De Bourdeaudhuij, I. M. (2006). Increasing children's physical activity levels during recess periods in elementary schools: The effects of providing game equipment. European Journal of Public Health, 16(4), 415-419. doi:10.1093/eurpub/ck1008

Webber, K., \& Loescher, L. (2013). A systematic review of parent role modeling of healthy eating and physical activity for their young African American children. Journal for Specialists in Pediatric Nursing, 18(3), 173-188.

Weiss, R. (1974). The provisions of social relationships. In Z. Rubin (Ed.), Doing unto others (pp. 1726). Englewood Cliffs, NJ: Prentice Hall.

Wick, K., Leeger-Aschmann, C. S., Monn, N. D., Radtke, T., Ott, L. V., Rebholz, C. E., . . Kriemler, S. (2017). Interventions to promote fundamental movement skills in childcare and kindergarten: A systematic review and meta-analysis. Sports Medicine, 47(10), 2045-2068. doi:10.1007/s40279017-0723-1

Wilson, K.S., Spink, K.S., \& Priebe, C.S. (2010). Parental social control in reaction to a hypothetical lapse in their child's activity: The role of parental activity and importance. Psychology of Sport and Exercise, 11, 231-237.

Wilson, \& Spink. (2011). Antecedents and consequences of family social control use following an adolescent physical activity lapse. Psychology of Sport \& Exercise, 12(6), 621-627.

Zahnd, W. E., Smith, T., Ryherd, S. J., Cleer, M., Rogers, V., \& Steward, D. E. (2017). Implementing a nutrition and physical activity curriculum in head start through an academic-community partnership. Journal of School Health, 87(6), 465-473. doi:10.1111/josh.12515

Zecevic, C. A., Tremblay, L., Lovsin, T., \& Michel, L. (2010). Parental influence on young children's physical activity. International Journal of Pediatrics, 2010, 468526. doi:10.1155/2010/468526

Zeng, N., Ayyub, M., Sun, H., Wen, X., Xiang, P., \& Gao, Z. (2017). Effects of physical activity on motor skills and cognitive development in early childhood: A systematic review. Biomed Research International, 2017, 2760716. doi:10.1155/2017/2760716 
Corresponding Author Information Daniela A. Rubin, Ph. D. (ORCID: 0000-0003-1578-8251) Professor in Kinesiology 800 N. State College Blvd.

Department of Kinesiology, KHS 138

California State University Fullerton

Fullerton, CA, 92834-3599, USA

drubin@fullerton.edu

Tel: 657-278-4704 / Fax: 657-278-5317 